Research Article

\section{Cell Biology International}

10.1002/cbin.10916

\title{
Extracellular matrix remodeling and TGF-ß1/Smad signaling in diabetic colon mucosa ${ }^{\dagger}$
}

Running title: Cell matrix and TGF- $\beta 1 /$ Smad in diabetic colon

Maria Cecilia D’Arpino ${ }^{1}$, Alicia G. Fuchs², Sara S. Sánchez ${ }^{1}$, Stella M. Honorée ${ }^{1 *}$.

${ }^{1}$ Instituto Superior de Investigaciones Biológicas (INSIBIO) Consejo Nacional de Investigaciones Científicas y Técnicas - Universidad Nacional de Tucumán (CONICET-UNT), Chacabuco 461, T4000ILI San Miguel de Tucumán, Argentina.

${ }^{2}$ Centro de Altos Estudios en Ciencias Humanas y de la Salud (CAECHIS)-Universidad Abierta Interamericana (UAI), Av. Montes de Oca 745, 1270AAH, Ciudad Autónoma de Buenos Aires, Argentina

MCD Recipient of CONICET Fellowship. SSS and SMH Career Investigators of CONICET.

Corresponding author: Stella M. Honoré, PhD

E-mail: smhonore@fbqf.unt.edu.ar

Tel /Fax: 54-381-4107214 ext 111

'This article has been accepted for publication and undergone full peer review but has not been through the copyediting, typesetting, pagination and proofreading process, which may lead to differences between this version and the Version of Record. Please cite this article as doi: [10.1002/cbin.10916]

This article is protected by copyright. All rights reserved

Received: 20 September 2017; Revised: 12 November 2017; Accepted: 30 November 2017 


\begin{abstract}
Diabetes is associated with metabolic and functional alterations in the gut. Using an experimental model of streptozotocin (STZ)-induced diabetes in rodents, we analyzed the extracellular matrix (ECM) and TGF- $\beta$ /Smad signaling in the colon mucosa. Male rats were divided into normal control, diabetic and insulin treated diabetic groups during 4 and 9 weeks. Sirius red staining showed marked increase in the extracellular matrix deposition in diabetic mucosa. High levels of fibrillar collagen (I and III) and fibronectin mRNAs were also detected with an imbalance between MMPs/TIMPs activities. Moreover, an increased mesenchymal cell proliferation together with an enhanced expression of myofibroblasts markers vimentin and $\alpha$-SMA were observed. TGF- $\beta /$ Smad signaling-related genes were determined using RT-PCR, western blotting, and immunohistochemistry. Diabetic rats showed a significant upregulation of TGF- $\beta 1$, TGF- $\beta$ receptors and the effectors $\mathrm{p}-\mathrm{Smad} 2 / 3$ in the mucosa compared with control rats. Insulin treatment attenuated the stimulating effect of diabetes on colon ECM deposition and TGF$\beta /$ Smad signaling. In conclusion, the overall results showed a deregulation of the TGF $\beta 1$ pathway associated with the appearance of myofibroblasts and the accumulation of ECM in the mucosa of diabetic colon. These data provide the first in vivo evidence that TGF- $\beta 1 /$ Smad is a key component of intestinal tissue remodeling in diabetes.
\end{abstract}

Key words: Diabetes, colon, extracellular matrix, myofibroblasts, MMPs, TGF- $\beta 1$.

Abbreviations: FGF, fibroblast growth factor; BMP, bone morphogenetic protein; EGF, epidermal growth factor; ECM, Extracellular matrix; MMPs, matrix metalloproteinase; TIMPs, metalloproteinase tissue specific inhibitors; TGF- $\beta$, transforming growth factor- $\beta$; TGF- $\beta$ R, transforming growth factor- $\beta$ receptor. 


\section{Introduction}

Diabetic gastroenteropathy is a highly heterogeneous and often an unpredictable diabetic complication. Its multiple symptoms as gastroesophageal reflux, dyspepsia, abdominal pain, diarrhea, constipation or fecal incontinence, affect more than $75 \%$ of patients, with a profound impact on their quality of life (Camillieri. 2002; Shakil et al., 2008).

While at present the identification of the diabetic bowel dysfunction are common due to the accessible methods for diagnosis, the investigation concerning the cellular and molecular mechanisms involved in the pathobiology of this complication is scarce. Prior studies have proposed altered intrinsic and extrinsic innervations of the lower gastrointestinal tract, as main responsible for the disturbances in motility, sensation, secretion, and absorption (He, 2001, Yoneda et al., 2001; Furlan et al., 2002; Honoré et al., 2011). However, a deeper biochemical and histomorphological changes seems to occur in the gastrointestinal tract with the progress of disease (Sanchez et al., 2001; Zhao et al., 2013; Dorfman et al., 2015). In this regard, impaired function of intestinal barrier was observed in type 1 diabetes patients and in animal models (Zanoni et al., 2008). Several reports have shown that diabetes can also alter the behavior of many drugs due to alterations in functional proteins as the intestinal epithelial transporters (Ogata et al., 2014). On the other hand, it is well known that insulin is required for the maintenance of a normal protein synthesis in the intestinal mucosa, required for the remodeling process of this fast turning over tissue. Thus, insulin deprivation in diabetes may be a contributing factor in the development of gastrointestinal complications (Haeusler et a., 2017).

Extracellular matrix (ECM) plays an active role in the maintenance and remodeling of tissues structure, being responsible for regulating numerous cellular processes such as proliferation, differentiation and migration (Hynes, 2009; Ahmed and French-Constant, 2016). ECM remodeling is a critical process during morphogenesis and tissue growth. Perturbation of its function has been implicated in pathological process. Under physiological conditions the normal turnover of ECM is regulated by many factors (growth factors, cytokines, chemokines, and proteolytic enzymes, among others) that ensure a delicate balance between synthesis and degradation process (Hyun-Jeong and Parks, 2007). The switch-over of this balance may conduct to excessive deposition of ECM with relevant clinical implications (Verrecchia, 2007). Particularly at intestinal level, several types of cells such as epithelial, resident mesenchymal cells (fibroblasts, myofibroblasts and smooth muscle cells) or marrow-derived stem cells can contribute to produce ECM proteins (Pucilowska et al., 2000; Andoh et al., 2007). Many factors like TGF- $\beta$, activins, EGF are able to activate the production of ECM in these cells (Mott and Werb, 2004; Verrecchia, 2007). On the other hand, ECM degradation is regulated by the enzymatic activity of a group of calciumactivated and zinc-dependent endopeptidases, the matrix metalloproteinase (MMPs) and their tissue specific inhibitors (TIMPs) (Clark et al., 2008; Brew and Nagase, 2010). 
TGF- $\beta$ family comprises multifunctional cytokines which regulate diverse cellular functions such as growth, adhesion, migration, apoptosis, differentiation and extracellular matrix synthesis (Massagué and Gomis, 2006; Massagué, 2008). Active TGF- $\beta$ signaling is transmitted through two types of transmembrane serine/threonine protein kinase receptor: TGF- $\beta$ type I (TGF- $\beta$ RI) and TGF- $\beta$ type II (TGF $\beta$ RII) (Kang et al., 2009). TGF- $\beta$ first binding to TGF- $\beta$ RII leads to heterotetrameric complex formation with the consequent TGF- $\beta$ RI phosphorylation (Massagué, 2008; Kang et al., 2009). Activated

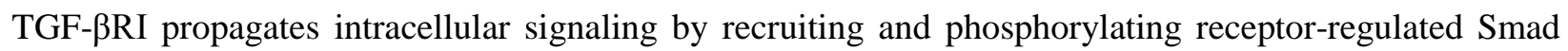
(R-Smad) proteins. Activated Smads form a complex with the common Smad (Smad4) which is translocate into the nucleus to regulate gene expression by binding to regulatory promoter DNA alone or interacting with other transcription factors (Ross and Hill, 2008).

Although high glucose is known to stimulate matrix synthesis in a variety of cell types, the participation of the ECM in diabetic enteropathy has not been fully understood. In this study, we evaluated the effects of diabetic environment in colon mucosa remodelling and examined the role of TGF- $\beta /$ Smad signaling in these events. Additionally, we also examined the possible therapeutic action of insulin on diabetic gut. The knowledge of cellular and molecular changes in diabetic colon could give valuable information not only from a mechanistic point of view but also in the clinical context about the intestinal damage related to diabetes. 


\section{Methods}

\subsection{Animals}

Male Wistar rats of 12 weeks old and with weights comprised between 250 and 300 g were used in this study. Rats were maintained throughout the experimental period under controlled conditions of temperature $\left(20-24^{\circ} \mathrm{C}\right)$, humidity (40-70\%) and standard conditions of photoperiod (12 h of light/12 h darkness) with free access to food and water. All the experiments were conducted in agreement with the Guide for the Care and Use of Laboratory Animals (Institute of Laboratory Animal Resources, Commission on Life Sciences, National Research Council, National Academy Press, Washington, DC), and the local Institutional Animal Care Committee.

\subsection{Streptozotocin-induced diabetes}

Diabetes was induced by a single intraperitoneal injection of streptozotocin (Sigma, St Louis, USA) (50 mg/kg body weight), freshly dissolved in $0.05 \mathrm{M}$ sodium citrate, $\mathrm{pH} 4.5$. Control animals were injected with the vehicle alone. Diabetic state was confirmed by measurement of tail blood glucose with a glucometer Accu-chek® Active (Roche Diagnostics GnbHD-68298 Mannhein, Germany). Only animals with glucose levels $\geq 300 \mathrm{mg} / \mathrm{dl}$ were included in the study.

\subsection{Experimental design}

Rats were then divided into six groups: (i) 4 weeks normal group ( $4, n=6)$, (ii) 4 weeks diabetic group (DM4, n =6), (iii) 4 weeks insulin-treated diabetic group (DM+I4, n=6), (iv) 9 weeks normal group (N9, $\mathrm{n}=6$ ), (v) 9 weeks diabetic group (DM9, $\mathrm{n}=6$ ), and (vi) 9 weeks insulin-treated diabetic group (DM+I9, $\mathrm{n}=6$ ). The $\mathrm{DM}+\mathrm{I}$ groups received daily insulin (5-10mUI of Insulin/b.w., Betasint), subcutaneously, to maintain serum glucose level at 80 to $160 \mathrm{mg} / \mathrm{dl}$. Weekly checks were performed to assess blood glucose levels as well as body weight in all experimental plots. At the end of the experiment, rats were deprived of food for $24 \mathrm{~h}$ and killed by cervical dislocation at 4 or 9 weeks after diabetes induction.

\subsection{Tissue sampling}

Proximal colon was dissected from the different groups of rats. The first centimeter close to the cecum was removed. From this point three pieces of proximal colon $(1 \mathrm{~cm})$ were cut and pinned down flat onto a glass dish with Sylgard silicone coating. The segments of colon were rinsed with ice-cold phosphatebuffered saline (PBS; pH 7.4) and immersed in fixative overnight at $4^{\circ} \mathrm{C}$ for classical histology and immunohistochemistry assays. The mucosa samples were obtained scraping off some segments using a glass slide and then stored at $80^{\circ} \mathrm{C}$ for further gene analysis. 


\subsection{Biochemical analyses}

Blood glucose was determined by using an Accu-chek Active tester (Roche Diagnostics GnbHD-68298 Mannhein, Germany) based on glucose dye oxido-reductase mediator reaction.

Plasma insulin was measured using an Enzyme-linked immunosorbent assay (Rat/mouse Insulin ELISA kit, Linco Research, Inc.) according to the manufacturer's protocol. Glycated Hemoglobin A1c (HbA1c) was isolated by a chromatographic method using a cationic exchange resin (Hemoglobin A1c Kit, BioSystem S.A, Barcelona-Spain) and quantified by spectrophotometrically at $415 \mathrm{~nm}$. Urinary glucose was determined with Micral-Test II (Boheringer Mannheim GmbH, Mannheim, Germany) reactive strips.

\subsection{Histology and Immunohistochemistry}

Intestinal tissue was fixed overnight in $4 \%$ formaldehyde in phosphate-buffered saline, embedded in paraffin and sectioned in $4 \mu \mathrm{m}$ slices. Sections were stained with H\&E for histological study, and Sirius red for the analysis of extracellular matrix. Picrosirius red stained sections were viewed using an Olympus BX80 microscope with polarization optics. The polarization birefringence colors were a measure of the collagen type, with a clear distinction from collagens type I (red) and type III (green). Immunohistochemistry was performed as was described previously (Honoré et al, 2011). Briefly, tissue sections were deparaffinized and the slides were immersed in $10 \mathrm{mM}$ citrate buffer (pH 6.0) and treated with microwave radiation to unmask binding epitopes prior to antibody staining. The slides were then left to stand for $10 \mathrm{~min}$ in buffer at room temperature before being thoroughly washed in tap water. Then they were treated with $3 \%(\mathrm{v} / \mathrm{v}) \mathrm{H}_{2} \mathrm{O}_{2}$ for 5 min, blocked with $10 \%(\mathrm{w} / \mathrm{v})$ normal goat serum for $1 \mathrm{~h}$, and then incubated with primary antibodies (see Table 1), at $4^{\circ} \mathrm{C}$ overnight. Slides were then incubated with appropriate biotin-conjugated secondary immunoglobulin $G$ and treated with streptavidin-peroxidase (Sigma). Color was developed by incubating with diaminobenzidine and counterstaining with hematoxylin. Negative control included omission of the primary antibody. All secondary antibodies were confirmed to be species-specific for their individual primary antibody and mismatched secondary antibody. The staining was not observed in the negative controls. Semiquantitative analysis of the percentage of positive staining was evaluated by a computer imaging analysis system using the Image $\mathrm{J}$ software (NIH Image). Brown areas were judged as positive. All scoring was performed in a blinded manner on coded slides using an Olympus BX80 microscope.

\subsection{Reverse-Transcription Polymerase Chain Reaction (RT-PCR)}

Total RNA was isolated from colon tissue using the Illustra RNAspin Mini Kit reagent (GE Healthcare) according to the manufacturer's protocol. $1 \mu \mathrm{g}$ RNA was reverse transcribed into first-strand cDNA using 
M-MLV Reverse Transcriptase (Promega) and oligo (dT) primers (Invitrogen). The expression of related genes was evaluated using on a Mastercycler personal instrument (Eppendorf, Germany). PCR was performed in optimized conditions: $95^{\circ} \mathrm{C}$ denatured for $10 \mathrm{~s}$ followed by 30 cycles of $5 \mathrm{~s}$ at $95^{\circ} \mathrm{C}, 5 \mathrm{~s}$ at $58^{\circ} \mathrm{C}$ and $35 \mathrm{~s}$ at $72^{\circ} \mathrm{C}$ and one cycle of $15 \mathrm{~s}$ at $95^{\circ} \mathrm{C}$. Specific PCR primers were designed from rat sequences available in the databanks: collagen type I, $\alpha 1$ (NM053304.1) forward primer 5'ACTGGCAACCTCAAGAAGTCCC-3' and reverse primer 5'-AAGTTCCGGTGTGACTCGTGC-3' ; collagen type III, $\alpha 1$ (NM032085.1) forward primer 5'- ACGCAAGGCCATGAGACTCC-3' and reverse primer 5'-GCAAACAGGGCCAATGTCCA-3'; fibronectin 1 (NM019143.2) forward primer 5'CAGTTGGTTGCCCTGTTCTGC-3' and reverse primer 5'-TCATTGCATCGTGGTTGGCTACC-3' ; smooth muscle alpha actin ( $\alpha$-SMA) (NM031004.2) forward primer 5'-CCCGCTCTGTCTCTAGCAC-3' and reverse primer 5'-CACACGAGTAACAAATCAAAGC-3'; MMP-1 (NM001134530.1) forward primer 5'-GAGGAGGGTCAACAGAGGAGC-3' and reverse primer 5'AACCCCAAAACCAAAGCAGCAATG-3'; MMP-2 (NM031054.2) forward primer 5'TCAAATCGGACTGGCTGGGC-3' and reverse primer 5'-AACCAGGCCTCTTCACGTCC-3'; MMP9 (NM031055.1) forward primer 5'-GAGGGGGAGGAGCTAGTTTGCC-3' and reverse primer 5'AAGGACAGCGTGCAGAGAGGG-3'; $\quad$ TIMP-1 (XM006256608.1) forward primer 5'GATTCGACGCTGTGGGAAATGCC-3' and reverse primer 5'-GATGAGAAACTCCTCGCTGCGG3'; TIMP-2 (NM021989.2) forward primer 5'-TGAATGGAAGCCCTCCCTGAGC-3' and reverse primer 5'-TACGAGGACAGCCAAGCACCC-3'; TGF- $\beta 1$ (NM021578.2) forward primer 5'GTGGCTGAACCAAGGAGACG-3' and reverse primer 5'-GGTGTTGAGCCCTTTCCAGG-3'; TGF$\beta$ RI (NM012775.2) forward primer 5'-ACCGCGTACCAAATGAAGAG-3' and reverse primer 5'TGTAGCACAATGGTCCTTGC-3'; $\quad$ TGF- $\beta$ RII $\quad$ (NM031132.3) forward primer 5'AGTTTTGCGACGTGACACTG-3' and reverse primer 5'-GGCATCTTCCAGAGTGAAGC-3'; $\beta$ actin (NM007393) forward primer 5'-CCGGCTTCGCGGGCGACG-3' and reverse primer 5'TCCCGGCCAGCCAGGTCC-3'. A negative control was performed using total RNA for each gene analyzed. The mRNA levels were standardized against $\beta$-actin mRNA levels. The mean value for the control animals was set at $100 \%$.

\subsection{SDS-PAGE Western Blot}

Colon was dissected and immediately frozen and stored at $-70^{\circ} \mathrm{C}$ until use. Intestinal mucosa were homogenized in buffer (Tris-HCL 50mM pH: 7.4; $\mathrm{NaCl}$ 0,1M; Nonidet P-40 1\%) supplemented with protease inhibitors (Halt protease inhibitor, cocktail kit, Pierce), EDTA, and imidazole (Invitrogen, CA, USA). Protein concentration was measured applying Lowry’s method (Lowry and Rosenbrouah, 1951). Samples containing $80 \mu \mathrm{g}$ of protein were mixed with loading buffer (Tris-HCl 0.0625M, pH 6,8; SDS 2\%; 2-mercaptoetanol 5\%; Sacarose 10\%; Bromophenol blue $0.002 \% ; \mathrm{H}_{2} \mathrm{O}(\mathrm{d})$ in the ratio $1: 4$ and 
electrophoresed in $7.5 \%$ polyacrylamide gels. Loaded proteins were blotted on a nitrocellulose membrane by electro transference (Sigma). Proteins detection was performed using specific primary antibodies

\section{(Table 1).}

\subsection{Zymography}

Gelatinase activity in the samples was determined by zymography as previously described

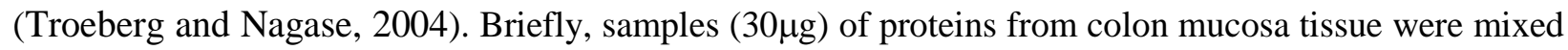
with sample buffer (SDS2\%, bromophenol blue 0.1\%, glycerol 40\%, Tris-HCL pH 6.8) and electrophoresed in $10 \%$ sodium dodecyl sulfate SDS-polyacrylamide gels, containing $10 \%$ gelatin. Gels were then renaturated al room temperature $90 \mathrm{~min}$ in buffer containing $200 \mathrm{mM} \mathrm{NaCl}, 5 \mathrm{mM} \mathrm{CaCl}, 5 \mu \mathrm{M}$ $\mathrm{ZnCl}_{2}$, 2.5\% Triton $\mathrm{x}-100,0.02 \% \mathrm{NaN}_{3}$, and $50 \mathrm{mM}$ Tris-HCl $\mathrm{pH}$.5), and then incubated overnight at $37^{\circ} \mathrm{C}$ in the same buffer without Triton $\mathrm{x}-100$. Gels were stained in $0.125 \%$ Coomassie blue R-250, 50\% methanol and 20\% acetic acid and stopped in 30\% methanol and 10\% acetic acid. Gelatinolytic activities were visualized as clear bands on a blue background and analyzed with the Gelanalyzer software.

\subsection{Statistical analysis}

The results from three independent in vivo experiments were presented as mean $\pm S D$. The significance of differences was evaluated using the paired Student's t-test. When more than one group was compared with one control, significance was evaluated by ANOVA followed by Tukey's post-test. A value of $\mathrm{p}<0.05$ was considered statistically significant. 


\section{Results}

\subsection{Clinical and biochemical parameters}

Table 2 shows the biochemical characteristics of the studied animals. Diabetes significantly increased blood glucose and glycated hemoglobin and decreased plasma insulin levels at 4 or 9 weeks compared to the age matched controls $(\mathrm{p}<0.05)$. Insulin treatment slightly improves the percentage of glycated hemoglobin in DM+I rats at 4 and 9 weeks.

\subsection{Intestinal parameters}

The body weight of diabetic rats significantly decreased compared with normal and insulin-treated diabetic rats along the experimental period $(\mathrm{p}<0.05)$. In addition, a significant increase in total length and weight of the colon in diabetic animals compared to those of the control group, was observed at short or long term. The hypertrophy index, measured as the ratio of colon weight / body weight was increased in diabetic animals from both experimental periods $(\mathrm{p}<0.05)$ (Table 3$)$.

\subsection{Structural alterations in diabetic colon mucosa}

Microscopic examination of diabetic colon sections showed qualitative changes in the mucosa layer compared with normal and insulin-treated diabetic rats. Morphometric analysis revealed a significant increase in crypt deep and in the thickness of the mucosa layer of the DM4 and DM9 animals compared to normal animals $(\mathrm{p}<0.05)$. Furthermore, an important cellular infiltrate in the lamina propria of the mucosa of DM9 and DM+I9 animals could be observed.

Examination of tissue sections stained with Sirius red (Fig. 1A) evidenced the presence of collagen as a thin line located in the base of the crypts epithelium and also in the connective tissue of the colon submucosa in N4 and N9 rats (a and $\mathbf{d}$ respectively). Interestingly a sharp increase in the affinity for the dye was observed as dense patches of collagen fibers in basal lamina and connective tissue surrounding the crypts in diabetic animals (b and e). The insulin treatment restored the staining patterning DM+I4 animals, but not in DM+I9 (f and c respectively). Quantitative analysis of serial sections confirmed the increase of total collagen content in DM4 (2.3-fold) and DM9 (2.5-fold) samples, compared to normal groups (Fig. 1B) $(\mathrm{p}<0.05)$. This increment was mainly due to collagen I at 4 weeks and to both types of collagen (I and III) at 9 weeks. Insulin treatment prevents collagen accumulation in DM+I4 mucosa. However, non-significant changes in the relative amount of collagen I was observed in DM+I9 respect to DM9 (p>0.05) (Fig. 2).

\subsection{ECM synthesis in diabetic colon mucosa}


To understand the ECM remodeling in the mucosa layer during diabetes, we examined synthesis and degradation process. RT-PCR analysis demonstrated that the collagen I, III and fibronectin mRNA levels were significantly higher in DM4 (mean 1.8-fold, 1.3-fold and 1.5-fold respectively) than in N4 samples (Fig. 3A) $(\mathrm{p}<0.05)$. Moreover, the expression of these mRNAs increased more in DM9 colons (mean collagen I: 2.3-fold; collagen III: 1.7-fold and fibronectin: 2.8-fold respectively) $(\mathrm{p}<0.05)$ (Fig. 3B). Insulin treatment restored the expression levels of the mRNAs of these matrix proteins in $\mathrm{DM}+\mathrm{I}$ groups showing a pattern similar to normal. However, it is important to note that DM+I9 animals maintained a high amount of fibronectin mRNA $(\mathrm{p}<0.05)$ (Fig. 3B).

\subsection{ECM degradation in diabetic colon mucosa}

Since ECM remodeling is modulated by the action of different MMPs and their TIMPs, we also investigated these molecules. RT-PCR analysis evidenced non-significant changes in MMP-1 mRNA expression in the mucosa in all analyzed groups at 4 weeks ( $>0.5$ ). However, MMP-2 and MMP-9 mRNA levels were significantly higher in DM4 (mean 2.3-fold and 1.8-fold) than in N4 and DM+I4 samples $(\mathrm{p}<0.05)$ (Fig. 4A).

At 9 weeks, the mRNA expression of MMP-1 and MMP-2 increased in the mucosa of DM9 colons (mean 2.7-fold and 0.5-fold) respect to N9 ( $\mathrm{p}<0.05)$. Insulin treatment restored MMP-2 levels but had no effects on MMP-1 in DM+I9 showing relative high amounts of this mRNA (mean 2.4-fold) ( $\mathrm{p}<0.05)$. MMP-9 expression was similar in all studied groups ( $\mathrm{p}>0.5$ ) (Fig. 4B).

The MMPs activities were evaluated by zymography analysis performed from mucosa homogenates of different experimental groups. Five of approximately 58, 79, 105, 123 y 134 kDa were detected (Fig. 5 A). Interestingly, a significant decrease in the activities of all detected metalloproteases, were observed in diabetic mucosa at 4 and 9 weeks $(\mathrm{p}<0.5)$. Insulin treatment improved all the MMPs activities at 4 weeks, but the activity of $123 \mathrm{kDa}-\mathrm{MMP}$ was only partially restored. At 9 weeks the activity of MMPs remains low and is not affected by insulin treatment ( $>0.5$ ) (Fig. 5B). Considering that MMPs activity is regulated by specific tissue inhibitors (TIMPs) we next investigated the expression of these molecules. Diabetes significantly increased TIMP-1 mRNA levels (mean 2.5-fold) $(\mathrm{p}<0.05)$, but only a slight increase of TIMP-2 transcripts in DM4 rats. No significant changes in TIMP-1 and TIMP-2 mRNA levels were detected at 9 weeks ( $>>0.05$ ) (Fig.1S Supplementary material).

\subsection{Diabetes causes changes in the myofibroblasts}

We investigated myofibroblast distribution in colonic mucosa to identify the potential cellular mechanisms that lead to intestinal MEC remodeling in early stages of diabetes. We analyzed the morphology, sub-epithelial location and positive immunoreactivity for $\alpha$-SMA and vimentin of these cells 
(Fig.6 A and B). The DM4 colon showed a higher number of $\alpha-\mathrm{SMA}^{+}$and vimentin ${ }^{+}$cells concentrated in the sub-epithelial region mainly at the base of the crypts. In contrast, only a small fraction of the cells are present in lamina propria of N4 colonic mucosa. A high $\alpha$-SMA expression remains even at later stages of disease, as shown by RT-PCR (Fig. 2S Supplementary material). The proliferation studies showed a significant increase of $\mathrm{Ki}^{+} 7^{+}$stained cells not only in the crypt epithelium but also in the sub-epithelial space around the crypts in DM4 animals, demonstrating a significant increase in proliferation rates in colon (30\%, p <0.05) compared with N4 group (Fig. 6C). On the other hand, TUNEL analysis showed no significant differences in the apoptotic processes in all the experimental groups studied ( $>0.05$ ).

\subsection{Diabetes altered TGF/Smad signaling in colon mucosa}

The effect of diabetes and insulin on TGF/Smad signaling-related genes throughout the colon was determined using RT-PCR. As shown in Fig. 7A, diabetes resulted in a significant increase of TGF- $\beta 1$ (3fold), TGF- $\beta$ RI (7-fold), TGF- $\beta$ RII (1.5-fold) mRNA levels in DM4 compared with N4 and D+I4 animals $(\mathrm{p}<0.05)$. At 9 weeks of diabetes, the mRNA expression of TGF- $\beta 1$, TGF- $\beta$ RI and TGF- $\beta$ RII significantly increased (1.8-fold; 1.8-fold and 1.6-fold respectively) compared with N9 and D+I9 animals $(\mathrm{p}<0.05)$ (Fig. 8A). Interestingly, insulin treatment restored the mRNA expression of all TGF signaling components to normal levels $(\mathrm{p}<0.05)$.

Western blot analysis showed an increased TGF- $\beta 1$ (1.6-fold), TGF- $\beta R I$ (1.7-fold) and pSmad2/3 (1.9fold) protein expression in DM4 colon mucosa, compared with N4 and D+I4 animals $(\mathrm{p}<0.05)$. While insulin treatment restored TGF- $\beta 1$ and TGF- $\beta$ RI expressions $(\mathrm{p}<0.05)$, pSmad2/3 remains increased at 4 weeks ( $\mathrm{p}>0.05$ ) (Fig. 7 B). Interestingly the TGF- $\beta 1$ ligand significantly increased in DM9 colon and insulin treatment did not have effect on it (Fig. 8B).

Given that phosphorylation and nuclear translocation of TGF- $\beta$ R activated p-Smads are the hallmarks of ongoing TGF- $\beta$ signaling, we analyzed p-Smad $2 / 3$ localization in the mucosa layer by immunohistochemistry (Fig. 7C and 8C). In diabetic animals, p-Smad 2/3 staining was strongly detected in crypt epithelial cells and in mesenchymal cells of lamina propria, with cytoplasmic and nuclear localization (b). In contrast, normal animals showed only few epithelial cells with a weak nuclear staining at the crypts (a). Insulin treatment fails to restore normal TGF- $\beta$ signaling activity (c) (Fig. 7C and 8C). 


\section{Discussion}

Diabetes mellitus leads to long-term alterations that affect the functionality of various organs and systems, including the gastrointestinal tract. Using an in vivo STZ-induced diabetic model, we demonstrated that hyperglycemia is associated with cellular and molecular changes in the colonic mucosa.

The maintenance of the normal tissue structure depends not only on a delicate balance between the processes of cell proliferation, migration, differentiation and apoptosis but also requires the continuous interaction of its cellular components and the ECM (Groos et al., 2001; Hynes, 2009). In the present study, we demonstrated that diabetic enteropathy is characterized by matrix accumulation and thickening of basement membrane in the colon mucosa. These changes are the result of an imbalance in the synthesis and degradation of ECM components, particularly type I and III collagens and fibronectin. Similar observations were evident in the muscle layer of diabetic jejunum (Sánchez, 2000).

We associate the increase in ECM synthesis with a significant increase of activated mesenchymal cells, especially myofibroblasts, in the lamina propria of diabetic colon. These cells exhibit a contractile phenotype characterized by the expression of $\alpha$-SMA and vimentin, and are capable to secrete large amounts of ECM (Powell et al., 2000; Sandbo and Dulin, 2011). It has recently been suggested that myofibroblasts may originate from various cellular types as local fibroblast populations, activated resident myofibroblasts, mesenchymal stem cells, and epithelial cells or through fibrocytes coming from the bone marrow (Hinz et al, 2012; Micallef et al., 2012). In our study the increased proliferation of myofibroblast detected in the lamina propria in diabetic mucosa, lead us to believe that the origin of these cells could be from resident myofibroblasts or fibroblasts. However, the possibility that the increased population of myofibroblasts in the diabetic colon could have another origin is not ruled out. Similar alterations were found in inflammatory bowel diseases where proliferation and differentiation of fibroblasts and myofibroblasts in the lamina propria were associated to an increased collagen deposition (Zorzi et al., 2015; de Souza, 2017).

Chronic hyperglycemia not only promotes matrix formation but also decrease its degradation in several tissues (McLennan et al., 2002). MMPs are endopeptidases that are responsible for degrading MEC molecules, thus taking part in the regulation of physiological and pathological processes (Hyun-Jeong and Parks, 2007). There are at least 25 types of these enzymes (Kirkegaard et al., 2004). Among them, MMP1, MMP-2 and MMP-9 have been associated with MEC remodeling processes in different organs (Giannandrea and Parks, 2014). Our results showed an increased expression early on gelatinases MMP-2, MMP-9 mRNAs and later in the collagenase MMP-1, in the diabetic colon mucosa. In line of this, it has been shown that myofibroblasts secrete MMP-2 and, upon stimulation, MMP-1, -3 and -9 having an active role in tissue remodeling during intestinal inflammation (McKaig et al., 2003; Kirkegaard et al., 
2004). Infiltrating macrophages and neutrophils were seen to be a major source of MMP-9 in human intestinal bowel disease and a mouse model of colitis in intestinal inflammation (Medina and Radomski, 2006) whereas MMP-1 is mainly produced by epithelial cells in response to inflammatory stimuli (Gao et al., 2005). In spite of transcriptional MMPs upregulation, low net matrix degrading activity in diabetic colon mucosa was observed by zymography. The enzymatic activity of the MMPs can be silenced by specific inhibitors of metalloproteases (TIMP1, 2, 3 and 4) which act by forming a 1:1 inactive complex, unable to bind substrate (Clark et al., 2008). In this work we find an increased expression of TIMP-1 and TIMP-2 which could result in decreased MMPs activities observed in diabetic colon mucosa. In addition, glycation of matrix components could affect the activities of the MMPs and thereby mediate indirectly some of the effects of chronic hyperglycemia, as was suggested by (McLennan et al., 2002).

The ECM has been also considered a source of inactive growth factors and other bioactive molecules which play an essential role in the overall matrix contribution to tissue homeostasis. These bound inactive factors could become unleashed upon matrix degradation initiatiating growth factor receptor signaling (Yu and Stamenkovic, 2000, Mott and Werb, 2004). In this sense, fibronectin-bound latent form TGF- $\beta$ is released to its active form in the presence of MMP-2 and MMP-9 (Yu and Stamenkovic, 2000). Recently, other studies reported that MMP-9 expression is positively related to events that promote excessive accumulation of ECM, through the regulation of TGF- $\beta 1$ expression (Krstic and Santibanez, 2014). Moreover, it has been shown that collagen and fibronectin are able to activate an integrin-dependent, transforming growth factor (TGF)- $\beta$ /Smad signaling, independently of TGF- $\beta$ or TGF- $\beta$ R (Garamszegi et al., 2010). Theses findings further enhance the contribution of ECM modulation on cellular behavior.

Bearing these factors in mind, we therefore analyzed the possible involvement of TGF- $\beta 1 /$ Smads pathway in diabetic colon mucosa. It is known that this signaling pathway is active in the gastrointestinal tract where it plays a critical role in intestinal homeostasis (Walters, 2005). In this regard we analyzed the expression of different components of this pathway. In experimental diabetes we observed a significant increase in the expression of both mRNA and protein TGF- $\beta 1$ in the mucosa layer. Recent studies have linked high levels of TGF- $\beta 1$ involved in the degenerative alterations that develop in the course of different intestinal pathologies such as Crohn's disease and in ulcerative colitis (Sedda et al., 2015; Zorzi et al., 2015). Similar results were observed in other experimental models of chronic inflammation of the rodent intestine (Lawrance et al., 2003).

Several lines of evidence suggest that chronic inflammation may promote excessive accumulation of ECM in tissues, triggering the onset of a fibrotic process and involvement of disease progression (Verrecchia and Mauviel, 2007; Hinz et al; 2012). As mentioned above, our results showed that the diabetic intestine is in an inflammatory microenvironment with an increased ECM deposition of collagen and fibronectin, concomitant with an activated TGF- $\beta 1$ pathway. This situation allows us to suggest that 
diabetes, could lead to a fibrogenic process in the gut taking into account that fibrosis is a chronic and progressive process characterized by excessive deposition of ECM components, particularly type I and III interstitial collagen (Pohlers et al., 2009; Hinz et al; 2012). Fibrotic lesions affect all organs and can result in disruption of the structure and affect their function (Verrecchia and Mauviel, 2007, Giannandrea and Parks, 2014).

Many in vitro studies have suggested that high levels of glycemia lead to increase non-enzymatic glycation of proteins, de novo synthesis of diacylglycerol and subsequent activation of protein kinase $\mathrm{C}$, characteristic of the diabetic microenvironment, increasing the production of TGF- $\beta$ and other cytokines(Chen et al., 2012). On the other hand, it has been determined that in damaged tissues TGF- $\beta 1$ can also be produced by immune cells, epithelial cells and/ or parenchymal cells (Hinz et al., 2012). It is probable that the inflammatory cells present in the lamina propria and submucosa of diabetic colons could be partially responsible for the increased production of TGF- $\beta 1$ in the intestine, as was observed in other pathologies (Andoh et al., 2007; Sans and Masamunt, 2006). In addition, there is experimental evidence that once activated, myofibroblasts also contribute to the production of TGF- $\beta$, so that they participate in the synthesis of MEC proteins as well as paracrine and autocrine factors mediating the fibrotic response (Andoh et al., 2007; Brenmoehl et al., 2009; Pohlers et al., 2009).

As we mentioned previously, TGF- $\beta 1$-mediated activation induces the translocation of the Smad2/3Smad 4 complex into the cell nucleus, where it directly promotes the expression of the white genes. By the end of 2000, 12 genes were known to contain Smads-regulated regions, including ECM molecules such as COL1A1 (Jimenez et al., 1994). Subsequently, by microarray studies the list was increased including white genes like COL3A1, COL5A2, COL6A3 and TIMP-1 (Verrecchia and Mauviel, 2007). Recent evidence suggests that Smad2/3 could also be activated by JNK, in the fibrotic process (Grynberg et al., 2017) suggesting that diabetes provides a complex metabolic environment of hormones, growth factors, and metabolic factors which may contribute to the pathogenesis of matrix accumulation.

In fact, all of the above-mentioned information allows us to conclude that TGF- $\beta 1$-mediated signaling would be involved in the remodeling of the mucosa layer in diabetes. This proposal is based on the fact that TGF- $\beta 1$, as mentioned above, activates myofibroblasts and induces the synthesis and accumulation of collagen in tissues. It inhibits its degradation through the increase of protease inhibitors and the suppression of proteolytic enzymes (Pucilowska et al., 2000; Giannandrea and Parks, 2014). NK directly phosphorylates SMAD3 to enhance transcription of pro-fibrotic molecules

In sum, our results suggest that ECM accumulation in diabetic enteropathy is predominantly mediated by hyperglycemia. However, we do not exclude any possible direct effect of insulin on the mechanism in matrix protein synthesis, as was suggested by diabetic nephropathy (Cao and Cooper, 2011). In addition, our results showed that insulin treatment could also modulate ECM degradation through MMPs activities which is relevant to increase matrix protein accumulation in diabetic intestine. The improvements of 
insulin treatment for diabetes-induced colon mucosa changes observed at 4-weeks, seems to be less effective with the progression of disease. Probably, despite strict glycemic control, variations in normal blood glucose levels may eventually occur as could be inferred from glycosylated hemoglobin levels. Thus, high glucose induced intracellular reactive oxygen species (ROS) and/or advanced glycosylation end product's accumulation could contribute to progressively alter the structure and function of proteins (such as collagen and fibronectin) in the intestinal wall during this hyperglycemia periods (Chen et al., 2012).

Together, our data provide the first in vivo evidence that TGF- $\beta 1 / \mathrm{Smad}$ is a key component of tissuespecific remodeling in diabetes associated with decreased turnover of ECM.

\section{Declaration of interest}

The authors declare that there is no conflict of interest that could be perceived as prejudicing the impartiality of the research reported

\section{Funding}

This research was supported by CONICET 11220110100529 (Argentina), PICT 20131949 (FONCyT Argentina) and PIUNT 2014 D549 (Argentina) grants to SSS and SMH. 


\section{References}

- Ahmed M, Ffrench-Constant C 2016 Extracellular Matrix Regulation of Stem Cell Behavior. Curr Stem Cell Rep. 2:197-206

- Andoh A, Bamba S, Brittan M, Fujiyama Y, Wright NA 2007 Role of intestinal subepithelial myofibroblasts in inflammation and regenerative response in the gut. Pharmacol Ther 114(1):94106

- Brenmoehl J, Miller SN, Hofmann C, Vogl D, Falk W, Schölmerich J, Rogler G 2009 Transforming growth factor-beta 1 induces intestinal myofibroblast differentiation and modulates their migration. World J Gastroenterol 15(12):1431-1442

- Brew K, Nagase H 2010 The tissue inhibitors of metalloproteinases (TIMPs): an ancient family with structural and functional diversity. Biochim Biophys Acta 1803:55-71

- Camilleri M (2002) Advances in diabetic gastroparesis. Rev Gastroenterol Disord 2:47-56

- Cao Z, Cooper ME 2011 Pathogenesis of diabetic nephropathy J Diabetes Investig. 2(4): 243-247

- Chen P, Zhao J, Gregersen H 2012 Up-Regulated Expression of Advanced Glycation End-Products and Their Receptor in the Small Intestine and Colon of Diabetic Rats. Dig Dis Sci 57:48-57

- Clark IM, Swingler TE, Sampieri CL, Edwards DR 2008 The regulation of matrix metalloproteinases and their inhibitors. Int J Biochem Cell Biol 40:1362-1378

- de Souza HS 2017 Etiopathogenesis of inflammatory bowel disease: today and tomorrow. Curr Opin Gastroenterol. 33(4):222-229

- Dorfman T, Pollak Y, Sohotnik R, Coran AG, Bejar J, Sukhotnik I 2015 Enhanced intestinal epithelial cell proliferation in diabetic rats correlates with $\beta$-catenin accumulation.J Endocrinol. 226(3):135143

- Fiocchi C 1998 Inflammatory bowel disease: etiology and pathogenesis. Gastroenterology 115:182-205

- Furlan MM, Molinari SL, Miranda Neto MH 2002 Morphoquantitative effects of acute diabetes on the myenteric neurons of the proximal colon of adult rats. Arq Neuropsiquiatr 60:576-581

- Gao Q, Meijer MJ, Kubben FJ, Sier CF, Kruidenier L, van Duijn W, van den Berg M, van Hogezand RA, Lamers CB, and Verspaget HW 2005 Expression of matrix metalloproteinases-2 and -9 in intestinal tissue of patients with inflammatory bowel diseases. Dig Liver Dis 37:584-592

- Garamszegi N, Garamszegi SP, Samavarchi-Tehrani P, Walford E, Schneiderbauer MM, Wrana JL, et al. 2010 Extracellular matrix-induced transforming growth factor-beta receptor signaling dynamics. Oncogene 29 (16):2368-2380

- Giannandrea M, Parks WC 2014 Diverse functions of matrix metalloproteinases during fibrosis. Dis Model Mech. 7(2):193-203 
- Grynberg K, Ma FY, Nikolic-Paterson DJ 2017 The JNK Signaling Pathway in Renal Fibrosis. Front Physiol. 8:829

- Haeusler RA, McGraw TE, Accili D 2017 Biochemical and cellular properties of insulin receptor signalling. Nat Rev Mol Cell Biol. doi: 10.1038/nrm.2017.89.

- He CL, Soffer EE, Ferris CD, Walsh RM, Szurszewski JH, Farrugia G 2001 Loss of interstitial cells of cajal and inhibitory innervation in insulin-dependent diabetes. Gastroenterology 121(2):427-34

- Heldin C, Landstrom M, Moustakas A 2009 Mechanism of TGF- $\beta$ signaling to growth arrest, apoptosis, and epithelial-mesenchymal transition. Current Opinion in Cell Biology, 21 (2): 166-176

- Hinz B, Phan SH, Thannickal V J, Prunotto M, Desmouliere A, Varga J, De Wever O, Mareel M, Gabbiani G 2012. Recent developments in myofibroblast biology: paradigms for connective tissue remodeling. Am. J. Pathol. 180, 1340-1355

- Honoré SM, Zelarayán LC, Genta SB, Sánchez SS 2011 Altered diabetic myenteric plexus is associated with an abnormal BMP/Smad signaling. Auton. Neurosc. Basic and Clinical 164:1-61

- Hynes RO 2009 Extracellular matrix:not just pretty fibrils.Science 326(5057):1216-1219

- Hyun-Jeong R, Parks WC 2007 Control of Matrix Metalloproteinase Catalytic Activity. Matrix Biol 26(8):587-596

- Jimenez SA, Varga J, Olsen A, Li L, Diaz A, Herhal J, Koch J 1994 Functional analysis of human alpha 1(I) procollagen gene promoter. Differential activity in collagen-producing and -nonproducing cells and response to transforming growth factor beta 1. J Biol Chem. 269(17):12684-12691

- Kang JS, Liu C, Derynck R 2009 New regulatory mechanisms of TGF- $\beta$ receptor function. Trends Cell Biol. 19, 385-394

- Kirkegaard T, Hansen A, Bruun E, Brynskov J 2004 Expression and localisation of matrix metalloproteinases and their natural inhibitors in fistulae of patients with Crohn's disease. Gut 53:701-9.

- Krstic J, Santibanez JF 2014 Transforming Growth Factor-Beta and Matrix Metalloproteinases: Functional Interactions in Tumor Stroma-Infiltrating Myeloid Cells The Scientific World Journal (2014), Article ID 521754, 1- 14 http://dx.doi.org/10.1155/2014/521754

- Lawrance IC, Wu F, Leite AZ, Willis J, West GA, Fiocchi C 2003 A murine model of chronic inflammation-induced intestinal fibrosis down-regulated by antisense NF-kappa B. Gastroenterology 125:1750-1761

- Massagué J 2008 TGF in cancer. Cell 134, 215-230

- Massagué J, Gomis RR 2006 The logic of TGFbeta signaling. FEBS Lett. 580:2811-2820

- McKaig BC, McWilliams D, Watson SA, Mahida YR 2003 Expression and regulation of tissue inhibitor of metalloproteinase-1 and matrix metalloproteinases by intestinal myofibroblasts in inflammatory bowel disease. Am J Pathol. 162:1355-1360 
- McLennan SV, Martell SKY, Yue DK 2002 Effects of mesangium glycation on matrix metalloproteinase activities possible role in diabetic nephropathy. Diabetes 51:2612-2618

- Medina C, Radomski MW 2006 Role of Matrix Metalloproteinases in Intestinal Inflammation. The journal of pharmacology and experimental therapeutics 318 (3):933-938

- Micallef L, Vedrenne N, Billet F, Coulomb B, Darby IA, Desmoulière A 2012 The myofibroblast, multiple origins for major roles in normal and pathological tissue repair. Fibrogenesis Tissue Repair. 5 (Suppl 1):S5

- Mott JD, Werb Z 2004 Regulation of matrix biology by matrix metalloproteinases. Curr Opin Cell Biol 16:558-564

- Ogata H, Seino Y, Harada N, Iida A, Suzuki K, Izumoto T, Ishikawa K, Uenishi E, Ozaki N, Hayashi Y, Miki T, Inagaki N, Tsunekawa S, Hamada Y, Seino S, Oiso Y 2014 KATP channel as well as SGLT1 participates in GIP secretion in the diabetic state. J Endocrinol. 222(2):191-200

- Pohlers D, Brenmoehl J, Loffler I, Muller CK, Leipner C, Schultze-Mosgau S, Stallmach A, Kinne RW 2009 Transforming growth factor-beta 1 and fibrosis in different organs- molecular pathway imprints. Molecular Basis of Disease 1792(8):746-756

- Pucilowska JB, Williams KL, Lund PK 2000 Fibrogenesis IV. Fibrosis and inflammatory bowel disease: cellular mediators and animal models. Am J Physiol Gastrointest Liver Physiol 279:653-659

- Ross S, Hill CS. 2008 How the Smads regulate transcription. Int J Biochem Cell Biol. 40(3):383-408

- Sánchez SS, Genta SB, Aybar MJ, Honoré SM, Villecco EI, Sánchez Riera AN 2000 Changes in the expression of small intestine extracellular matrix proteins in streptozotocin-induced diabetic rats. Cell Biol Int 24(12):881-888

- Sandbo N, Dulin N 2011 The actin cytoskeleton in myofibroblast differentiation: Ultrastructure defining form and driving function. Transl Res. 158(4): 181-196

- Sans M, Masamunt MC 2007 Fibrogénesis y enfermedad inflamatoria intestinal. Gastroenterol Hepatol. 30(1):36-41

- Sedda S, Marafini I, Dinallo V, Di Fusco D, Monteleone G 2015 The TGF- $\beta /$ Smad System in IBD Pathogenesis. Inflamm Bowel Dis. 21(12):2921-2925

- Shakil A, Church RJ, Rao SS 2008 Gastrointestinal complications of diabetes. Am Fam Physician 77(12):1697-1702

- Verrecchia F, Mauviel A (2007) Transforming growth factor-beta and fibrosis. World J Gastroenterol. 13(22):3056-3062

- Walters JR 2005 Recent findings in the cell and molecular biology of the small intestine. Curr Opin Gastroenterol. 21(2):135-140

- Yoneda S, Kadowaki M, Kuramoto H, Fukui H, Takaki M 2001 Enhanced colonic peristalsis by impairment of nitrergic enteric neurons in spontaneously diabetic rats. Auton Neurosci 92:65-71 
- Yu Q, Stamenkovic I 2000 Cell surface-localized matrix metalloproteinase-9 proteolytically activates TGF-beta and promotes tumor invasion and angiogenesis. Genes Dev 14:163-176

- Zanoni JN, Fernandes Pereira RV. 2008 Cell proliferation of the ileum intestinal mucosa of diabetic rats treated with ascorbic acid. Biocell 32(2):163-168

- Zhao J, Chen P, Gregersen H 2013 Morpho-mechanical intestinal remodeling in type 2 diabetic GK rats-is it related to advanced glycation end product formation? J Biomech. 46(6):1128-34

- Zorzi F, Calabrese E, Monteleone G 2015 Pathogenic aspects and therapeutic avenues of intestinal fibrosis in Crohn's disease. Clin Sci (Lond). 129(12):1107-13 


\section{FIGURE LEGENDS}

Figure 1. Effect of diabetes on intestinal ECM. A. Representative sections of colon mucosa of normal, diabetics and insulin treated-diabetic rats at 4 (a-c) and 9 (d-f) weeks of disease stained by Sirius red. Scale bar: $50 \mu \mathrm{m}$ (a-c) $100 \mu \mathrm{m}$ (d-f). B: Densitometric analysis of the stained sections. The mean values \pm $\mathrm{SD}$ of three experiments are expressed as a percentage of control. N, normal control rats; DM, diabetic rats; DM+I, insulin treated diabetic; ep, epithelium; lp, lamina propria; cc, globet cell; cl, Lieberkühn crypt. ${ }^{\mathrm{a}} p<0.05 \mathrm{DM}$ and $\mathrm{DM}+\mathrm{I}$ versus $\mathrm{N} ;{ }^{\mathrm{b}} p<0.05 \mathrm{DM}+\mathrm{I}$ versus $\mathrm{DM}$.

Figure 2. Effect of diabetes on the relative amounts of intestinal collagens. A. Representative sections of of Sirius red stained samples of colon mucosa of normal, diabetics and insulin treated-diabetic rats at 4 and 9 weeks of disease analyzed by Polarized microscopy. Scale bar: $50 \mu \mathrm{m}$. B: Densitometric analysis of the stained sections. The mean values \pm SD of three experiments are expressed as a percentage of control. $\mathrm{N}$, normal control rats; $\mathrm{DM}$, diabetic rats; $\mathrm{DM}+\mathrm{I}$, insulin treated diabetic; ep, epithelium; lp, lamina propria; cc, globet cell; cl, Lieberkühn crypt. ${ }^{\mathrm{a}} p<0.05 \mathrm{DM}$ and $\mathrm{DM}+\mathrm{I}$ versus $\mathrm{N}$; ${ }^{\mathrm{b}} p<0.05 \mathrm{DM}+\mathrm{I}$ versus DM.

Figure 3. Effect of diabetes on intestinal ECM synthesis. A: RT-PCR analysis of type I and III collagen and fibronectin gene expression from samples obtained from colon mucosa of normal, diabetics and insulin treated diabetic rats at 4 weeks of disease. The mean values \pm SD of three experiments expressed as a percentage of control are shown with representative gels. B: RT-PCR analysis of type I and III collagen and fibronectin gene expression from samples obtained at 9 weeks of disease. The mean values \pm SD of three experiments expressed as a percentage of control are shown with representative gels. $\mathrm{N}$, normal control rats; DM, diabetic rats; DM+I, insulin treated diabetic; M, molecular weight marker; (-) negative control. ${ }^{\mathrm{a}} p<0.05 \mathrm{DM}$ and $\mathrm{DM}+\mathrm{I}$ versus $\mathrm{N}$; ${ }^{\mathrm{b}} p<0.05 \mathrm{DM}+\mathrm{I}$ versus $\mathrm{DM}$.

Figure 4. Effect of diabetes on intestinal MMPs expression. A: RT-PCR analysis of MMP-1, MMP-2 and MMP-9 gene expression from samples obtained from colon mucosa of normal, diabetics and insulin treated diabetic rats at 4 weeks of disease. The mean values \pm SD of three experiments expressed as a percentage of control are shown with representative gels. B: RT-PCR analysis of the same MMPs at 9 weeks of disease. The mean values \pm SD of three experiments expressed as a percentage of control are shown with representative gels. N, normal control rats; DM, diabetic rats; $\mathrm{DM}+\mathrm{I}$, insulin treated diabetic; $\mathrm{M}$, molecular weight marker; (-) negative control. ${ }^{\mathrm{a}} p<0.05 \mathrm{DM}$ and $\mathrm{DM}+\mathrm{I}$ versus $\mathrm{N}$; ${ }^{\mathrm{b}} p<0.05 \mathrm{DM}+\mathrm{I}$ versus DM. 
Figure 5. Effect of diabetes on colon mucosa MMPs activity. A: Representative zymogram results obtained from colon mucosa of normal, diabetics and insulin treated diabetic rats at 4 and 9 weeks of disease. B: Densitometric analysis of the detected bands. The mean values \pm SD of three experiments expressed as a percentage of control are shown with representative gels. ${ }^{a} p<0.05 \mathrm{DM}$ and $\mathrm{DM}+\mathrm{I}$ versus $\mathrm{N} ;{ }^{\mathrm{b}} p<0.05 \mathrm{DM}+\mathrm{I}$ versus DM.

Figure 6. Effect of diabetes on mucosa myofibroblast markers and proliferation. Immunostaining of $\alpha$-SMA (A) and Vimentin (B) in colon mucosa of normal and diabetics rats at 4 weeks of disease. Scale bar: $50 \mu \mathrm{m}$. The mean values \pm SD of three experiments expressed as a percentage of control. C: Immunostaining of Ki67 in colon mucosa of normal and diabetics rats at 4 weeks of disease. Scale bar: $50 \mu \mathrm{m}$. The mean densitometric values \pm SD of three experiments expressed in arbitrary units. $\mathrm{N}$, normal control rats; DM, diabetic rats; DM+I, insulin treated diabetic; M, molecular weight marker; (-) negative control; ep, epithelium; lp, lamina propria; cc, globet cell; cl, Lieberkühn crypt. ${ }^{a} p<0.05$ DM and DM+I versus $\mathrm{N} ;{ }^{\mathrm{b}} p<0.05 \mathrm{DM}+\mathrm{I}$ versus $\mathrm{DM}$.

Figure 7. Effect of early diabetes on intestinal expression of TGF- $\beta$ /Smad signaling. A: RT-PCR analysis of TGF- $\beta /$ Smad-related gene expression from samples obtained from colon mucosa of normal, diabetics and insulin treated diabetic rats at 4 weeks of disease. B: Representative results of Western blot analysis of TGF- $\beta 1$, TGF- $\beta$ RI and p-smad 2/3 obtained from corresponding samples. C: Immunostaining of p-smad 2/3 in intestinal mucosa. Note nuclear staining (arrows) in diabetic colons. Scale bar: $50 \mu \mathrm{m}$. Insert magnification: $40 \mathrm{X}$. The mean values \pm SD of three experiments expressed as a percentage of control. N, normal control rats; DM, diabetic rats; DM+I, insulin treated diabetic; M, molecular weight marker; (-) negative control; ep, epithelium; lp, lamina propria; cc, globet cell; cl, Lieberkühn crypt. ${ }^{a} p<$ $0.05 \mathrm{DM}$ and $\mathrm{DM}+\mathrm{I}$ versus $\mathrm{N} ;{ }^{\mathrm{b}} p<0.05 \mathrm{DM}+\mathrm{I}$ versus $\mathrm{DM}$.

Figure 8. Effect of late diabetes on intestinal expression of TGF- $\beta$ /Smad signaling. A: RT-PCR analysis of TGF- $\beta /$ Smad-related gene expression from samples obtained from colon mucosa of normal, diabetics and insulin treated diabetic rats at 9 weeks of disease. B: Representative Western blot of TGF$\beta 1$ protein. C: Immunostaining of $\mathrm{p}$-smad 2/3 in intestinal mucosa. Note nuclear staining (arrows) in diabetic colons. Scale bar: $50 \mu \mathrm{m}$. Insert magnification: $40 \mathrm{X}$. The mean values \pm SD of three experiments expressed as a percentage of control. N, normal control rats; DM, diabetic rats; DM+I, insulin treated diabetic; M, molecular weight marker; (-) negative control; ep, epithelium; lp, lamina propria; cc, globet cell; cl, Lieberkühn crypt. ${ }^{\mathrm{a}} p<0.05 \mathrm{DM}$ and DM+I versus $\mathrm{N}$; ${ }^{\mathrm{b}} p<0.05 \mathrm{DM}+\mathrm{I}$ versus DM. 
Table 1. Antibodies used.

Table 2. Biochemical features of animals in study.

Table 3. Clinical features of animals in study.

\section{APPENDIX A. SUPPLEMENTARY DATA}

Figure 1S. Effect of diabetes on the intestinal TIMPs expression. A. RT-PCR analysis of TIMP-1 and TIMP-2 gene expression from samples obtained from colon mucosa of normal, diabetics and insulin treated-diabetic rats at 4 and 9 weeks of disease. B: RT-PCR analysis of same TIMPs at 9 weeks of disease. The mean values \pm SD of three experiments expressed as a percentage of control are shown with representative gels. $\mathrm{N}$, normal control rats; $\mathrm{DM}$, diabetic rats; $\mathrm{DM}+\mathrm{I}$, insulin treated diabetic; $\mathrm{M}$, molecular weight marker; (-) negative control. ${ }^{\mathrm{a}} p<0.05$, significantly different from control; ${ }^{\mathrm{b}} p<0.05$, significantly different from diabetic.

Figure 2S. Effect of diabetes on intestinal $\alpha$-SMA expression. A. RT-PCR analysis of $\alpha$-SMA gene expression from samples obtained from colon mucosa of normal, diabetics and insulin treated diabetic rats at 4 weeks of disease. B: RT-PCR analysis at 9 weeks of disease. The mean values \pm SD of three experiments expressed as a percentage of control are shown. N, normal control rats; DM, diabetic rats; $\mathrm{DM}+\mathrm{I}$, insulin treated diabetic; $\mathrm{M}$, molecular weight marker; (-) negative control. ${ }^{\mathrm{a}} p<0.05 \mathrm{DM}$ and $\mathrm{DM}+\mathrm{I}$ versus $\mathrm{N} ;{ }^{\mathrm{b}} p<0.05 \mathrm{DM}+\mathrm{I}$ versus $\mathrm{DM}$. 
Table 1

Antibodies used.

\section{Host Dilution* Catalogue no. Source}

\begin{tabular}{lllll}
\hline Primary antibody & & & & \\
$\alpha$-SMA & Mouse & $1: 100$ & A2547 & Sigma \\
Vimentin & Goat & $1: 100$ & V4630 & Sigma \\
Ki-67 & Rabbit & $1: 100$ & AB9260 & Millipore \\
TGF- $\beta 1$ & Rabbit & $1: 50$ & sc-146 & Santa Cruz Biotech \\
TGF- $\beta$ receptor I & Rabbit & $1: 50$ & Sc-400 & Santa Cruz Biotech \\
p-Smad2/3 & Goat & $1: 100$ & Sc-11769 & Santa Cruz Biotech \\
Y-Tubulin & Rabbit & $1: 500$ & T3569 & Sigma \\
& & & & \\
Secondary antibody & & & & \\
Biot anti-goat IgG & Rabbit & $1: 750$ & B7014 & Sigma \\
Biot anti-mouse IgG & Goat & $1: 750$ & B2010 & Sigma \\
Biot anti-rabbit IgG & Mouse & $1: 250$ & B3275 & Sigma \\
ExtrAvidin ${ }^{\circledR}$-phosphatase & & $1: 3000$ & E2636 & Sigma \\
\hline * Dilution used in immunohistochemical and westernblot studies. &
\end{tabular}


Table 2

Biochemical features of animals in study

\begin{tabular}{lccc}
\hline & $\begin{array}{c}\text { Blood Glucose } \\
(\mathrm{mg} / \mathrm{dl})\end{array}$ & $\begin{array}{c}\text { Glycated hemoglobin } \\
(\% \mathrm{HbA} 1 \mathrm{C})\end{array}$ & $\begin{array}{c}\text { Plasma insulin } \\
(\mathrm{ng} / \mathrm{ml})\end{array}$ \\
\hline $\mathrm{N} 4$ & $118.67 \pm 4.92$ & $6.03 \pm 1.48$ & $2.39 \pm 0.09$ \\
$\mathrm{DM} 4$ & $479.00 \pm 16.81^{\mathrm{a}}$ & $14.49 \pm 0.50^{\mathrm{a}}$ & $0.35 \pm 0.07^{\mathrm{a}}$ \\
$\mathrm{DM}+14$ & $102.00 \pm 25.82$ & $8.83 \pm 2.32^{\mathrm{b}}$ & $0.58 \pm 0.23^{\mathrm{a}}$ \\
$\mathrm{N} 9$ & $113.00 \pm 4.00$ & $6.50 \pm 1.28$ & \\
$\mathrm{DM} 9$ & $479.25 \pm 32.04^{\mathrm{a}}$ & $12.96 \pm 0.34^{\mathrm{a}}$ & $0.41 \pm 0.15^{\mathrm{a}}$ \\
$\mathrm{DM}+19$ & $127.08 \pm 29.51$ & $9.30 \pm 0.77^{\mathrm{a}, \mathrm{b}}$ & $0.71 \pm 0.35^{\mathrm{a}, \mathrm{b}}$ \\
\hline
\end{tabular}

Data are mean \pm SD. $\mathrm{n}=6$ animals per group.

${ }^{\mathrm{a}} p<0.05 \mathrm{DM}$ and $\mathrm{DM}+\mathrm{I}$ versus $\mathrm{N} ;{ }^{\mathrm{b}} p<0.05 \mathrm{DM}+\mathrm{I}$ versus $\mathrm{DM}$.

Table 3

Clinical features of animals in study

\begin{tabular}{lllc}
\hline & Final body weight $(\mathrm{g})$ & Colon lenght $(\mathrm{g})$ & $\begin{array}{c}\text { Ratio colon weight / } \\
\text { body weight (\%) }\end{array}$ \\
\hline N4 & $379.43 \pm 9.43$ & $8.25 \pm 0.30$ & $0.12 \pm 0.02$ \\
DM4 & $235.15 \pm 47.72^{\mathrm{a}, \mathrm{b}}$ & $10.85 \pm 0.40^{\mathrm{a}, \mathrm{b}}$ & $0.32 \pm 0.02^{\mathrm{a}, \mathrm{b}}$ \\
$\mathrm{DM}+14$ & $308.80 \pm 19.45^{\mathrm{a}}$ & $8.25 \pm 1.00$ & $0.14 \pm 0.01$ \\
& & & \\
N9 & $456.35 \pm 14.25$ & $9.75 \pm 0.75$ & $0.18 \pm 0.02$ \\
DM9 & $212.30 \pm 12.56^{\mathrm{a}, \mathrm{b}}$ & $12.05 \pm 0.76^{\mathrm{a}, \mathrm{b}}$ & $0.54 \pm 0.07^{\mathrm{a}, \mathrm{b}}$ \\
$\mathrm{DM}+19$ & $358.20 \pm 33.16^{\mathrm{a}, \mathrm{b}}$ & $11.25 \pm 0.25$ & $0.23 \pm 0.02^{\mathrm{a}}$ \\
\hline
\end{tabular}

Data are mean \pm SD. $\mathrm{n}=6$ animals per group.

${ }^{\mathrm{a}} p<0.05 \mathrm{DM}$ and $\mathrm{DM}+\mathrm{I}$ versus $\mathrm{N} ;{ }^{\mathrm{b}} p<0.05 \mathrm{DM}+\mathrm{I}$ versus $\mathrm{DM}$. 
Figure 1

A.

Picrosirius Red
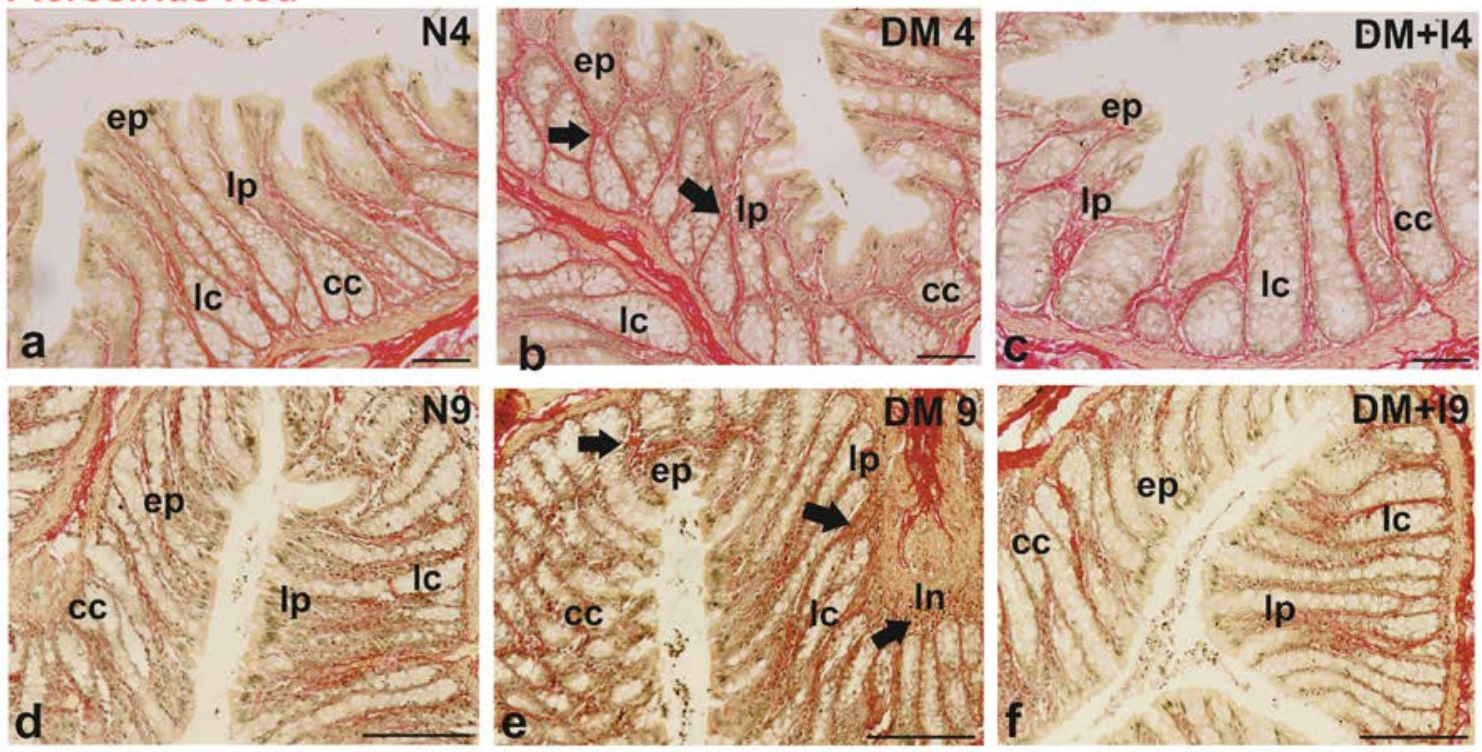

B.

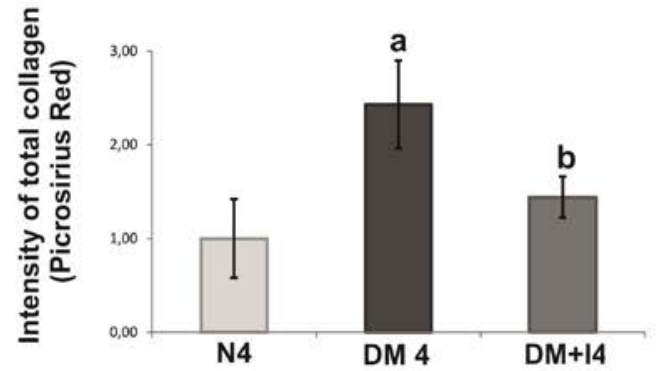

C.

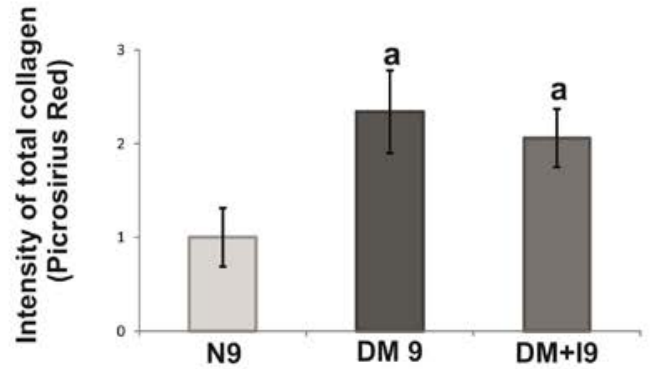




\section{Figure 2}

A.

Picrosirius Red
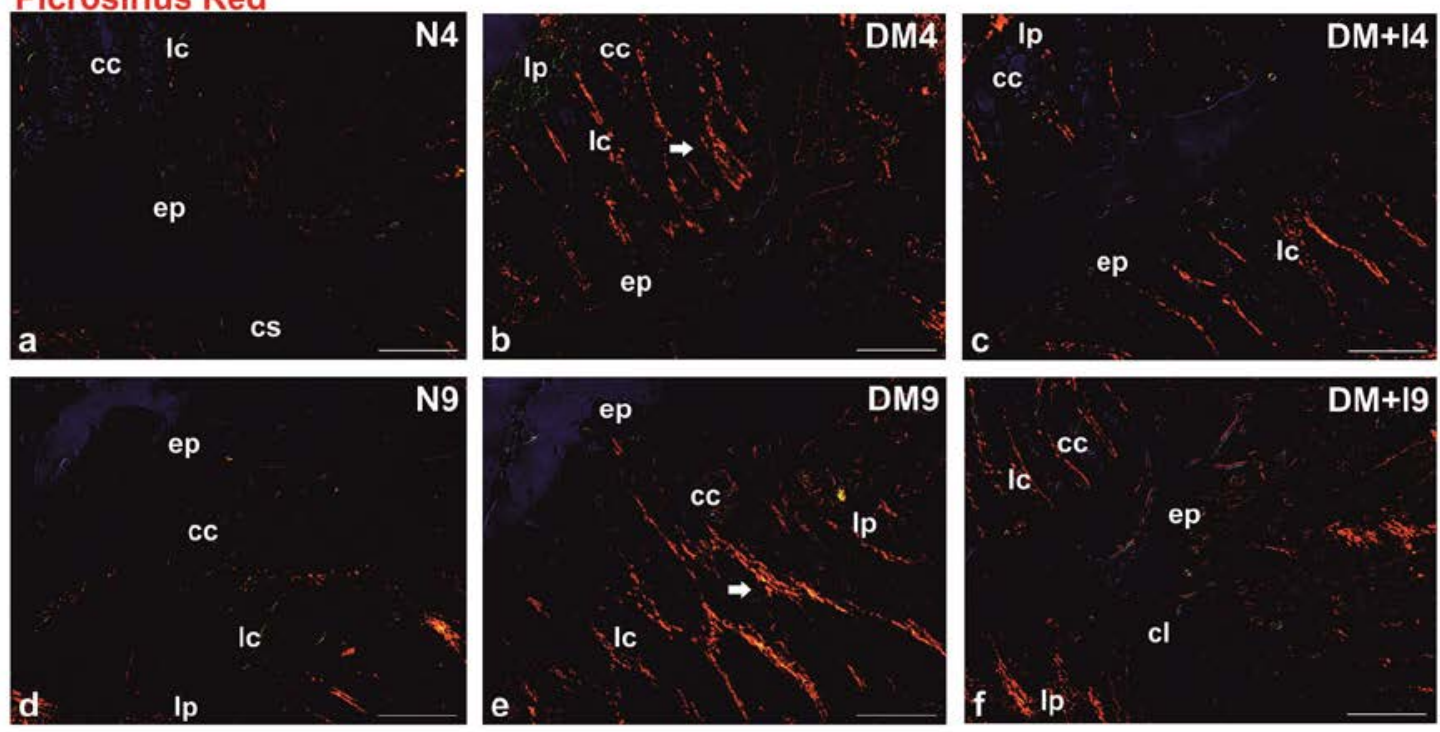

B.

C.
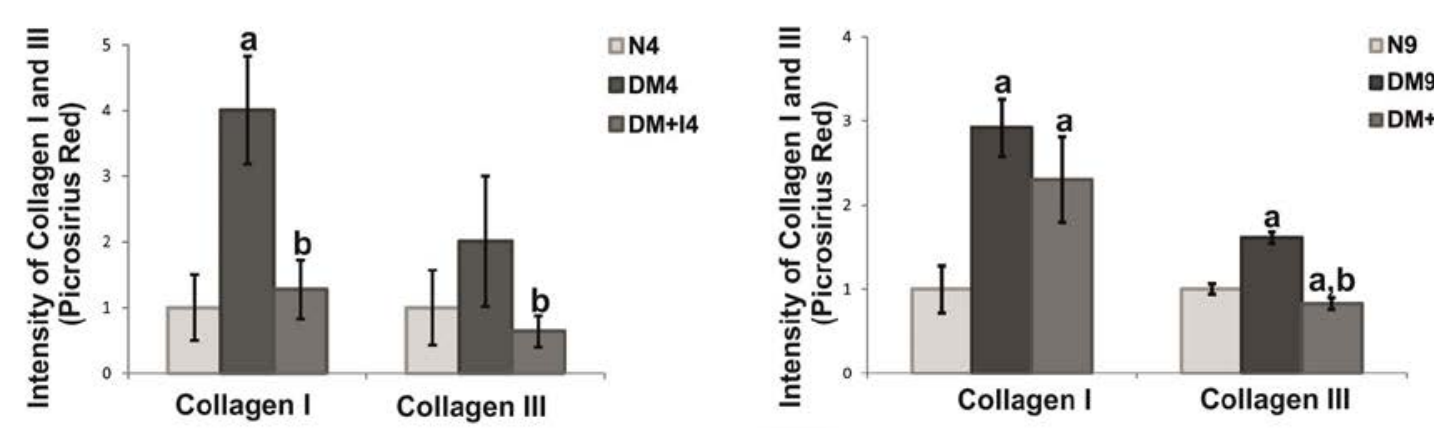
Figure 3

A.

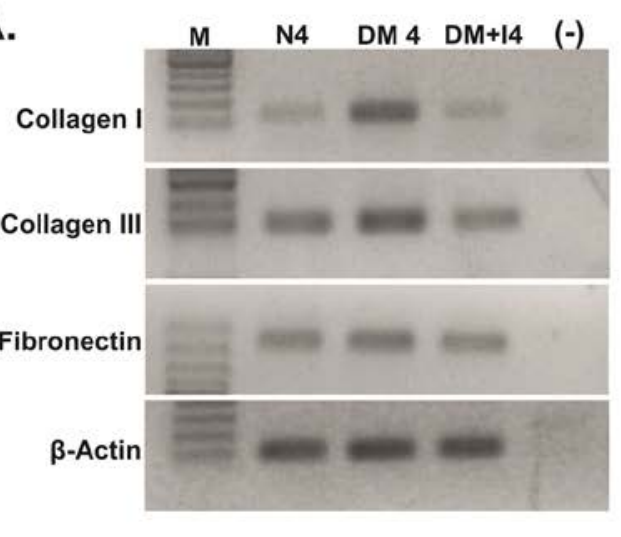

c.

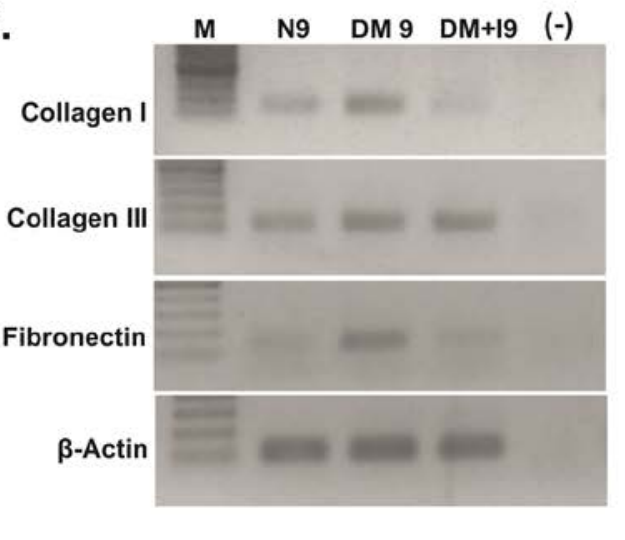

B.

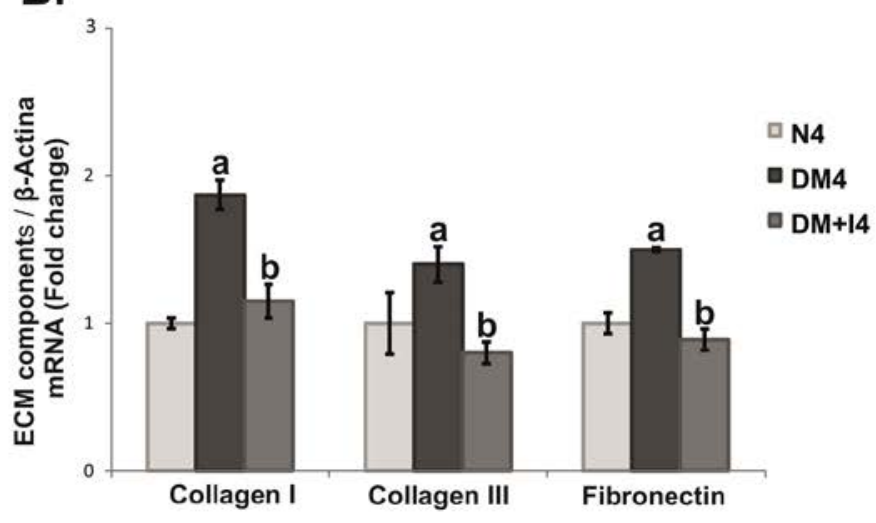

D.

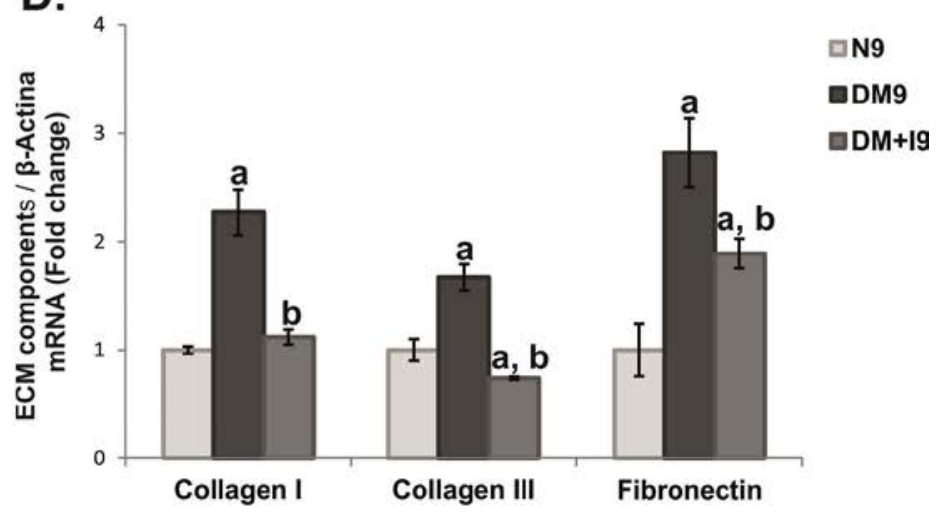


Figure 4

A.

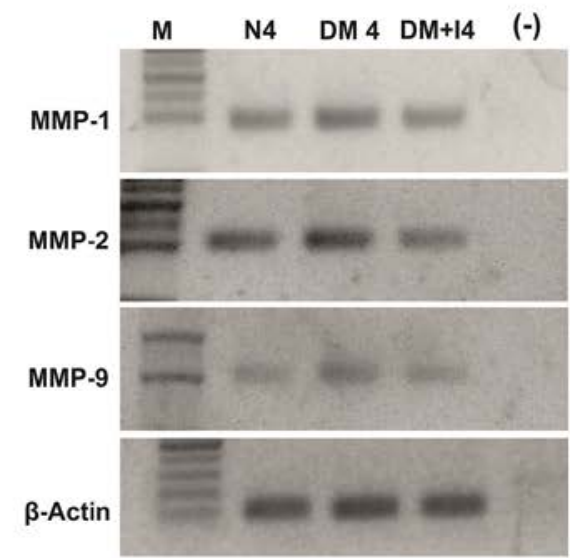

c.

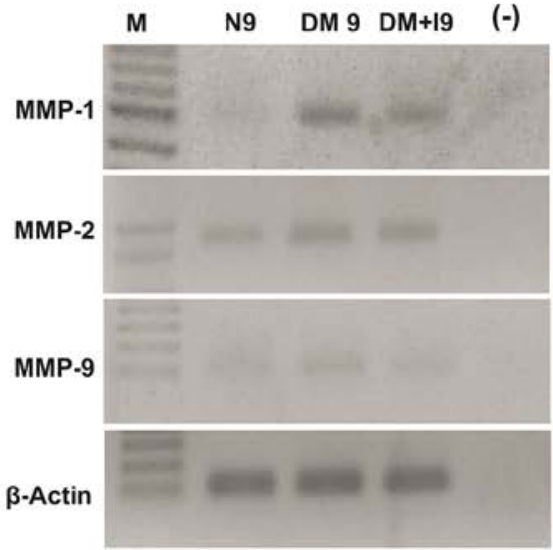

B.

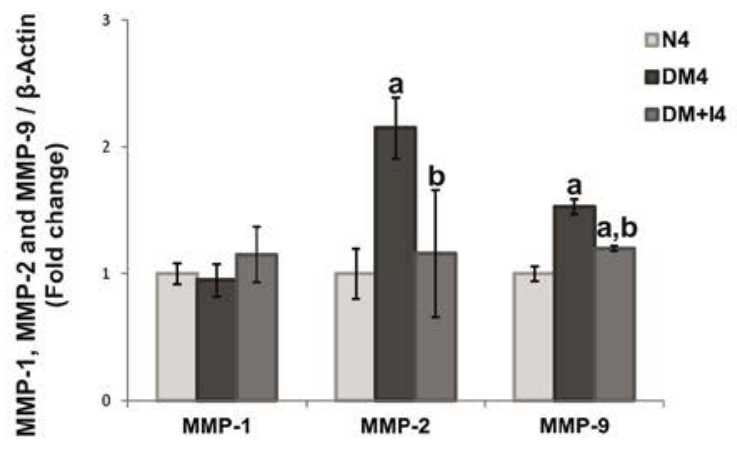

D.

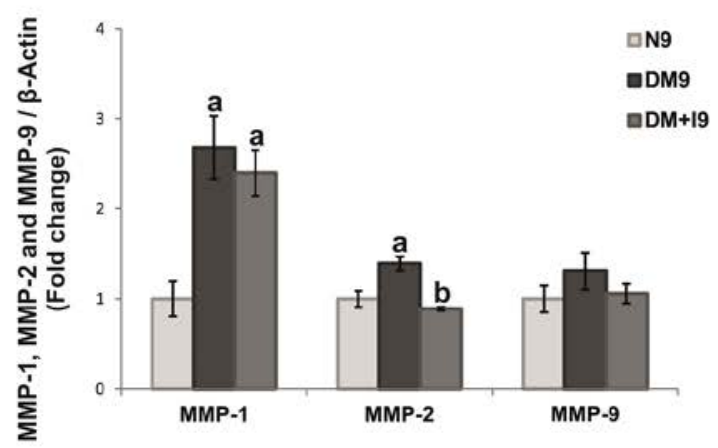


Figure 5

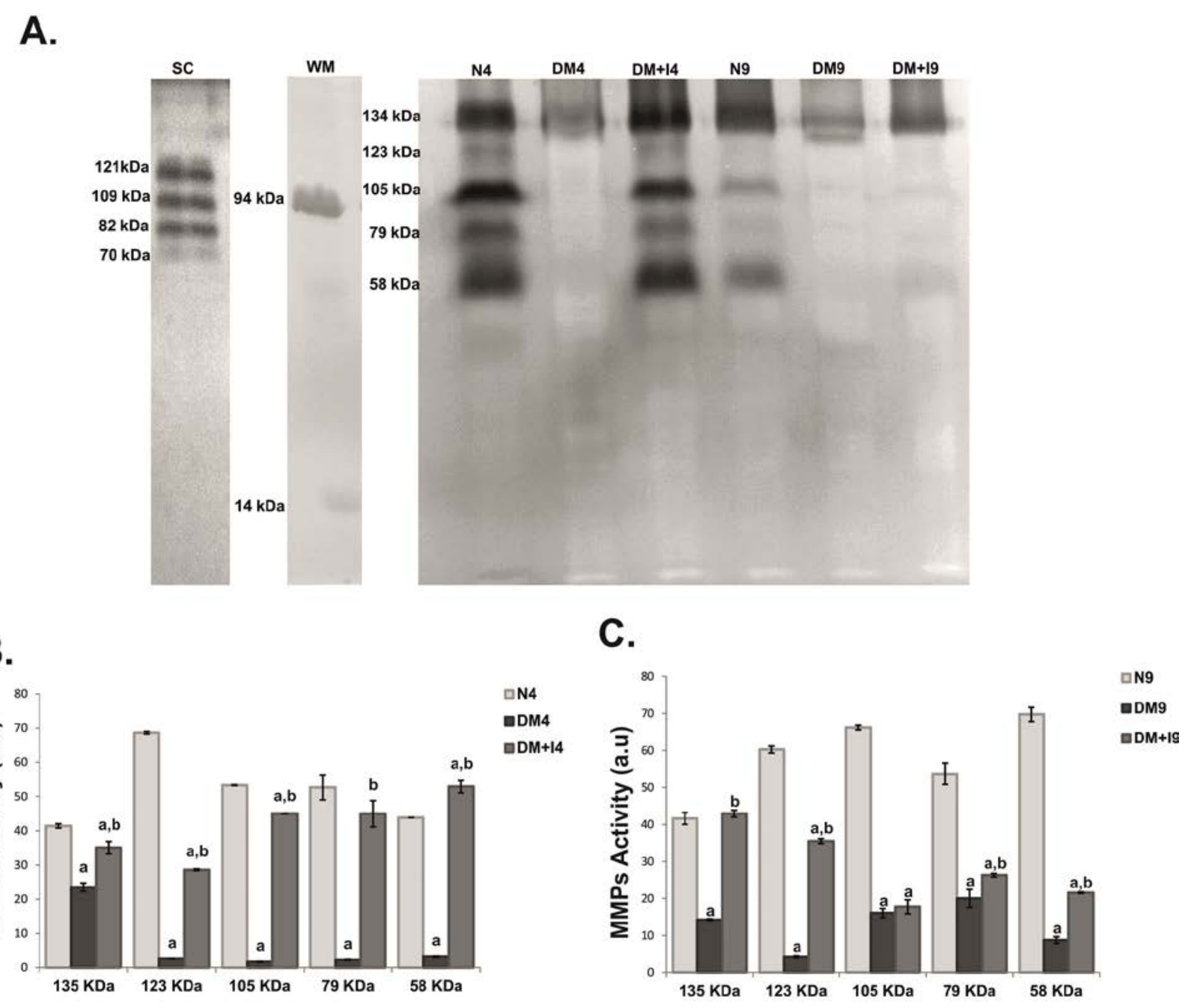


Figure 6

A. $\alpha-S M A$

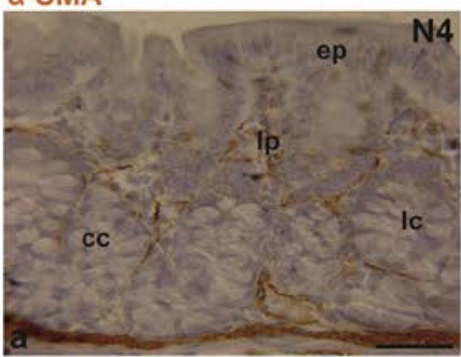

C. Vimentina

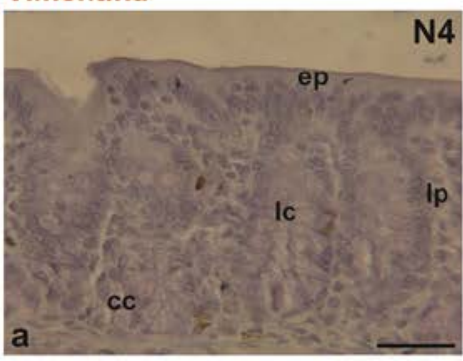

E. $\mathrm{Ki} 67$

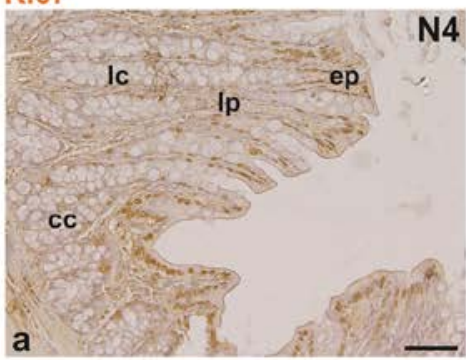

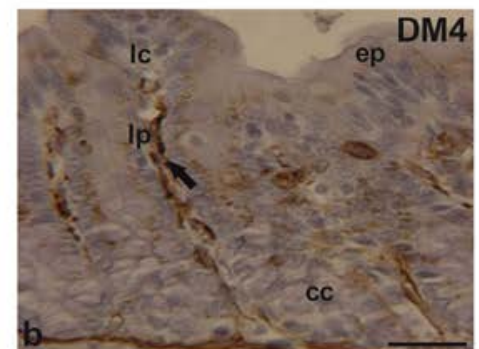
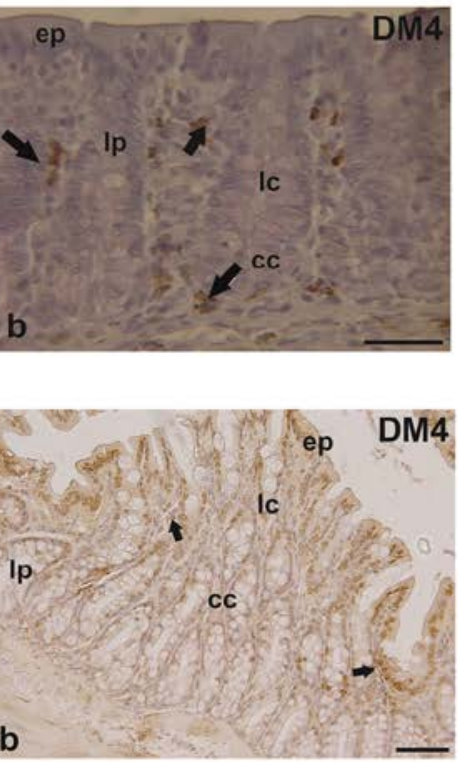

B.

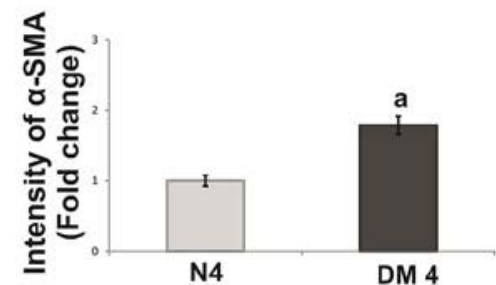

D.

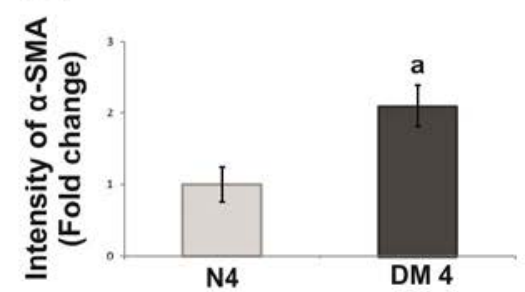

F.

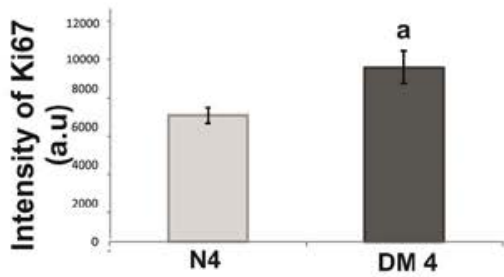




\section{Figure 7}

A.

B.

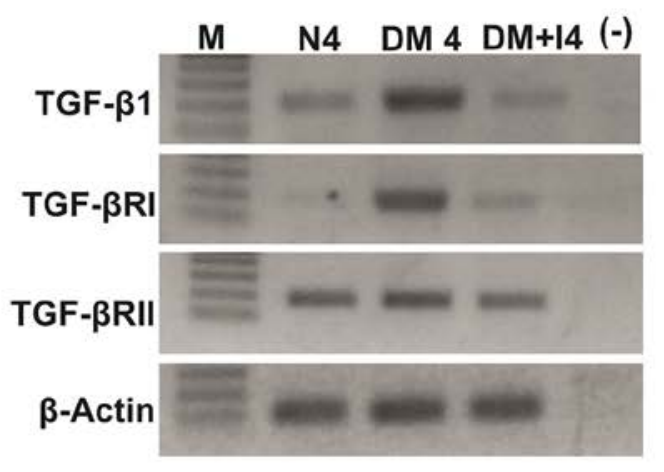

C.
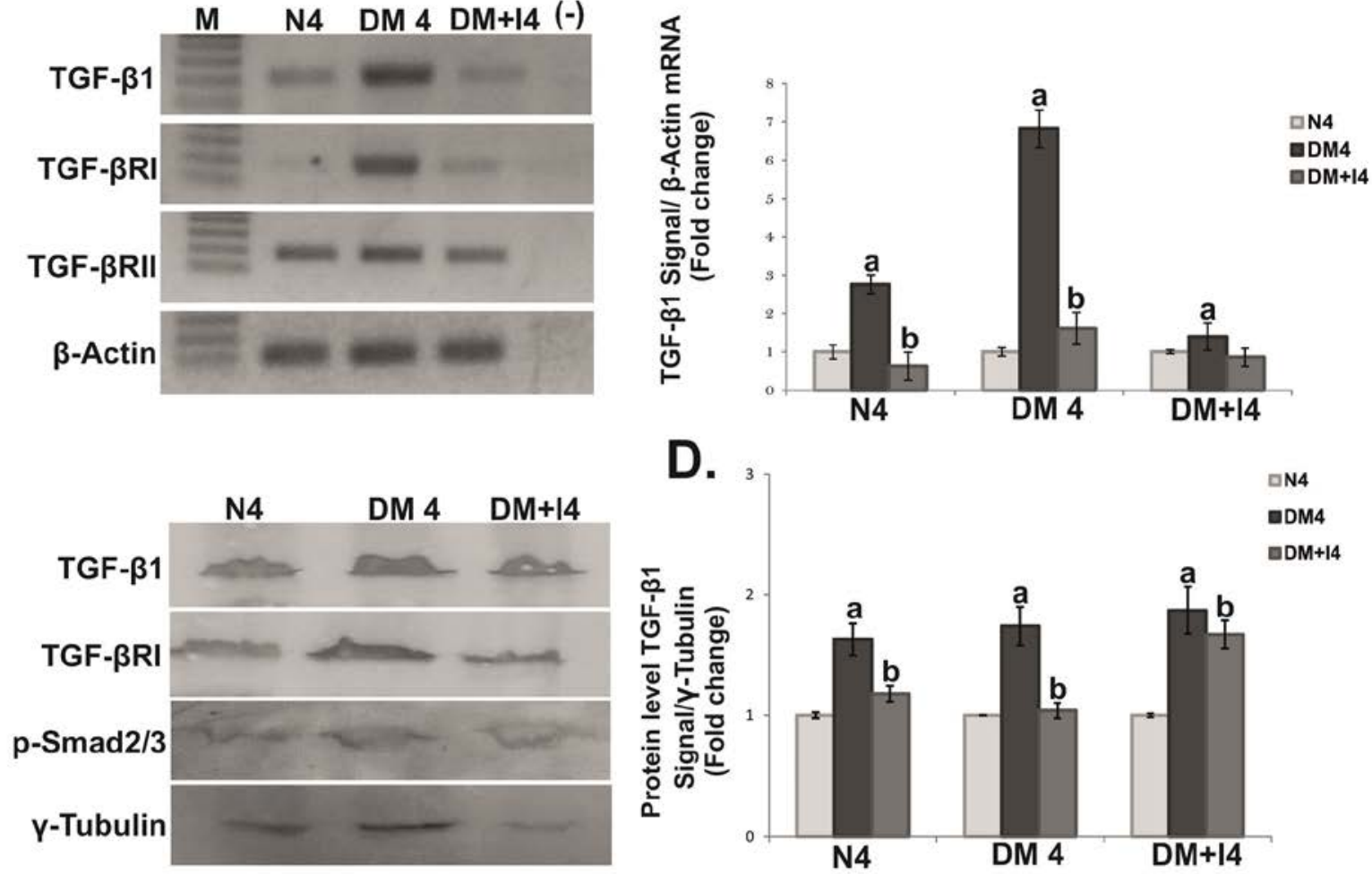

E.

pSmad 2/3
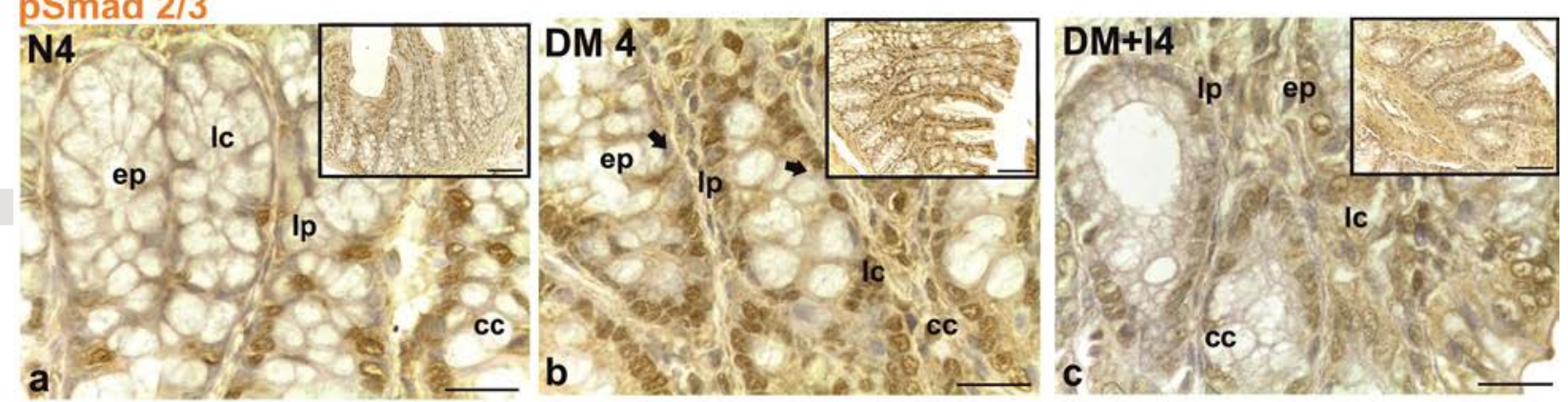

F.

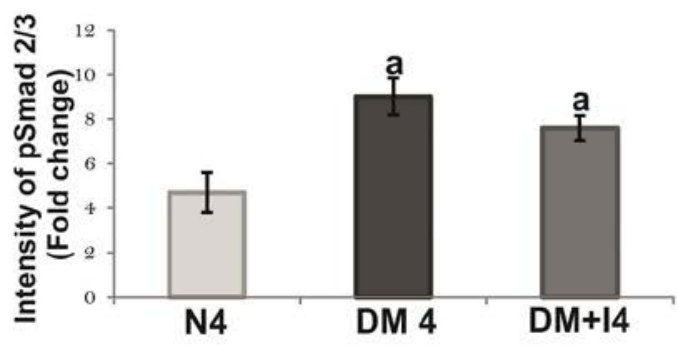


Figure 8

A.
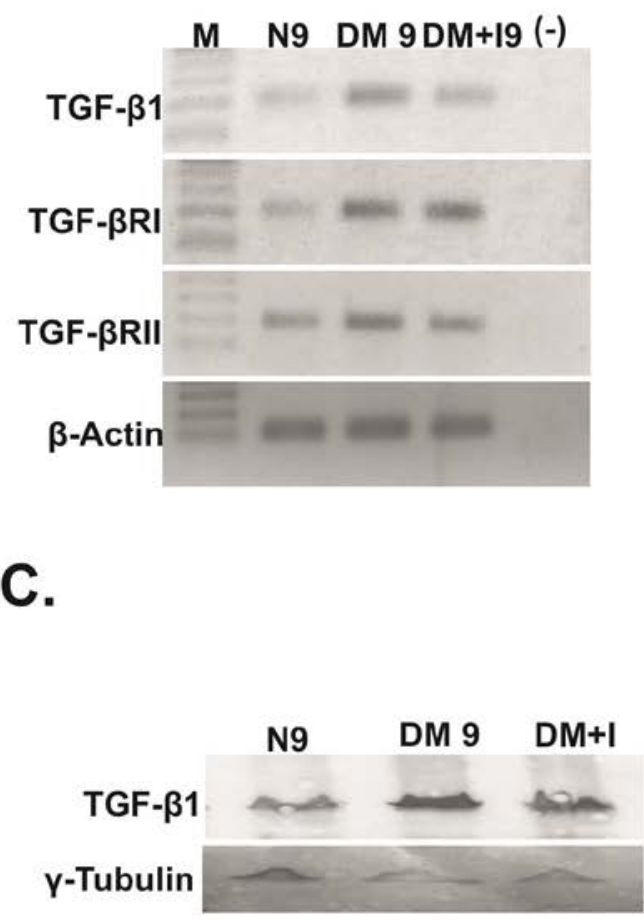

E.
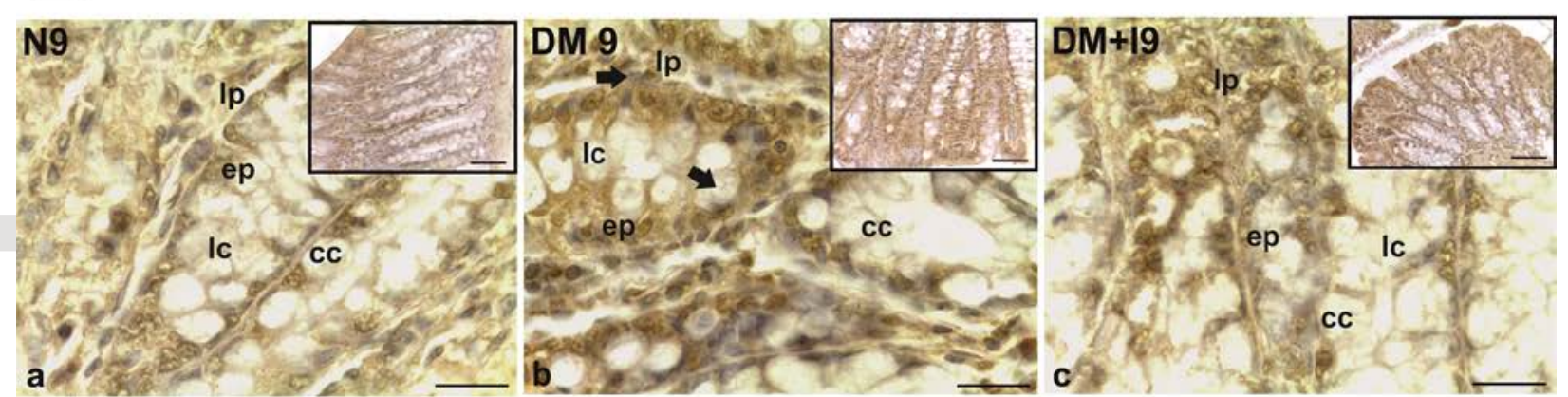

F.

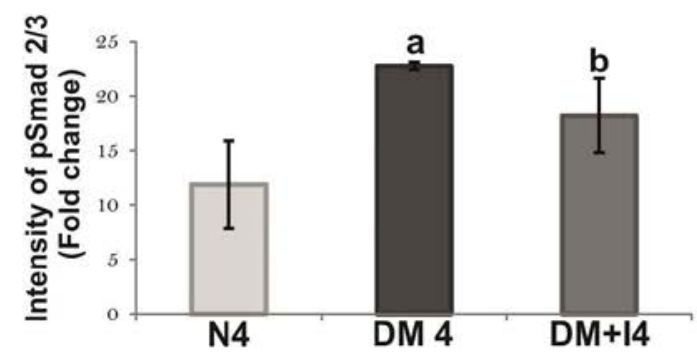

